\title{
Management of Aging Workers Generations in the Context of Corporate Social Responsibility
}

\author{
Joanna Gajda \\ Czestochowa University of Technology, Częstochowa, Poland
}

\begin{abstract}
Management of aging workers generation is connected closely with a corporate social responsibility strategy, because according to its principles, the organization is obliged to allow implementations of operations for rational to use the potential of employees being involved for all sorts age groups. Creating the even playing field on-the-job causes the growth of the commitment of employees into building the dialogue among generations. In this article, a management system was described with age, including plains and areas on which he is carried out. Moreover was directed employees' attention to useful tools one should consciously apply to the purpose of effective managing of the age. Expressed tools mutually are completing themselves, creating the system of integrated actions what positively is being transferred into functioning of the organization.
\end{abstract}

Keywords: aging workers, corporate social responsibility, management

\section{Introduction}

Modern organizations conducting business in less predictable environments understand that in order to succeed in the rapidly growing market, it is important to seek to attract and retain the potential of employees of different ages. Any action taken in this regard should be a standard element of the organization and cover the different phases of employment the employee - from recruitment after departure from work. Therefore, they are of age management areas. This concept is also reflected in the social responsibility of businesses, which, thanks to the skillful use of workforce management instruments diverse in terms of age is conducive to their professional activation contributing in this way to improve the organization's performance. Currently, an important issue is the problem of how corporate social responsibility can be regarded as the true state of commitments consistent with the strategy of the organization of human resource management, and not as a sign of ill-considered actions.

\section{Corporate Social Responsibility and Human Resource Management}

Reviewing the literature on the subject is easy to see that corporate social responsibility is most often understood as a strategy by which the activities in a business organization aim not only to maximize profits, but on the basis of regulations and ethical obligations to take into account the expectations of stakeholders (Adamczyk, 2009). In the case of an organization, having a responsible attitude causes moral issue allowing the decision dilemma, which is good for all individuals and groups interested in the possibility of entry to the

Joanna Gajda, Ph.D., Czestochowa University of Technology, Częstochowa, Poland.

Correspondence concerning this article should be addressed to Joanna Gajda, Bialska 59/3, 42-200 Częstochowa, Poland. E-mail: joannagajda@vp.pl. 
organization interact and what is bad. As stated by Michalski (2008), only this organization can meet its obligations to the environment, when it is able to bear the economic and legal responsibility; it will consistently aim to meet social objectives, if they help to increase economic efficiency.

Socially responsible organizations base their activities on the assumption that their actions do not bring the desired effect, if you will be directed exclusively to its external environment. Therefore, it is reasonable to make efforts to internal stakeholder employees to which they belong (Barrena-Martínez, López-Fernández, \& Romero-Fernandez, 2011). It seems obvious that the performance of their work depends on increasing the efficiency of the organization's activities in the market and consequently, this will lead to its competitive advantage. It is worth noting that the subordinates with high productivity, regardless of age, are considered to be the main tool used to generate profits. First of all for this reason, the companies' operations should be undertaken in the first instance to the employees of different ages and tightly integrated with corporate social responsibility (Buciuniene \& Kazlauskaite, 2012).

Management of human resources in a responsible manner is the responsibility of each organization functioning in the market, which is characterized by a serious approach to corporate social responsibility and should be emphasized that the human resources department should demonstrate exceptional sensitivity in matters related to corporate social responsibility. It cannot just be the reason why the organization is taking it as a tool to create the underlying or improve self-image. Meanwhile, it is noteworthy that corporate social responsibility translates into organizational culture and constitutes the foundation on which the organization builds its own identity on the basis of the existing values or ethical codes.

Implementation of the daily practice of valuable solutions can positively affect employee morale, to improve the performed work and increase loyalty to the company. It undoubtedly affects the economic efficiency of the organization, because of the followings (Szydłowska-Biskup, 2015):

- Employee is well rewarded with a desire to come to work and engages in the execution of his duties;

- The worker is fixed in the belief that working for a unique organization that cares for its sense of stability does not want to leave such a place of work;

- Staff will be happy to present another opinion on what the company can improve the organization's image and attract the most sought after professionals in the market.

\section{Legal Levels of Corporate Social Responsibility and Age Management in Organizations}

Corporate social responsibility is a strategy that refers to two dimensions of action-external and internal. The first includes activities aimed at business partners and the local community and the global environment. The second relates to initiatives for the internal environment. Thus, an integral part of the strategy chosen by the organization can be a socially responsible management concept age. It boils down to the implementation of measures to enable effective management of human resources, taking into account both the needs and capabilities of employees of different ages.

Among the activities addressed to all employees regardless of age, commitment stands out to help shape the working conditions adequate to their needs, increase their motivation to better performance and job satisfaction, build relationships with them desirable, and create opportunities for employees and their potential with benefit for themselves and for the organization.

All the solutions proposed by organizations as part of corporate social responsibility are implemented on the basis of constitutional values, resulting from the regulation, however, it is observed that sometimes it 
goes beyond behaviors consistent with these standards. On the basis of such a legal perspective adopted, it becomes necessary to separate the two levels. The first is related to the complement of the obligations under the law, on the basis of actions taken as positive and necessary for the proper performance of these duties. The second is on creating readiness to implement the organization of voluntary practices adopted beyond the legal obligations, but they are back on the system of values resulting from secondary legislation. This is in particular the normalization of constitutional and international law (Bernatta, Bogdanienko, \& Skoczny, 2011).

Considering the first level, taking into account the legal aspect of the concept of corporate social responsibility, it is necessary to comply with the principle of equality organizations and non-discrimination. The first principle is against age discrimination in employment, which means that the employees cannot be treated unequally by the employer. As a result, this could lead to termination of employment, wage disadvantage, or exclusion from promotion. An example of behavior contrary to the strategy of corporate social responsibility is the termination of employment, due to the age of the employee with reference to the reasons for the seemingly objective.

The organization meeting the requirements of the second level in relation to employment, decides to implement practices aimed at preventing discrimination and violation of the dignity of the employee and care for the equal treatment of employees in terms of paying for doing the same work, regardless of their age. Businesses should take action to prepare importing these jobs to be free from discrimination, regardless of any reason. Therefore, there is a need to provide training in which all employees participated, regardless of age. In the case of emerging behaviors of unlawful discrimination, the employer is obliged to immediately respond (Biernatt, 2009).

\section{Nature and Age Management Areas}

Making considerations for the management of aging should focus on trying to determine the substance of the term. Today, age management is defined as the set of rules, methods, and instruments relating to employment, ability to perform work affecting the achievement of economic and social productivity throughout the life and conduct healthy lifestyles of the employees of all ages taking into account the period of retirement. Any action taken with regard to age management enables to effectively manage human potential, including mature workers over 50 years of age (Liwiński \& Sztanderska, 2010a).

Age management boils down to focus its activities on the growth of labor productivity in the team, which also includes older workers. The activities are designed to prepare such an environment and organization of work that will prove to be friendly to all employees regardless of age or position held jobs (Urbaniak \& Wieczorek, 2007). Among the proposals inscribed in age management philosophy, by the method of occupying a special place to invest in human capital development organization to each team member, staff are able to benefit from their work and feel satisfied with it. Age management encompasses a number of activities classified into the following groups (Szcześniak, 2013):

- employment planning;

- recruitment of employees using the principle of non-discrimination on grounds of age;

- improvement of skills in order to acquire new competencies;

- flexible forms of employment;

- plan of jobs and health programs; 
- development and promotion of employees 50+;

- end of employment and entry into the retirement period (Barrena-Martínez, López-Fernández, \& Romero-Fernández, 2012).

It should be noted that the use of management tools age selectively leads to the desired effect. It is advisable to adopt a comprehensive approach involving the implementation of activities in each of the specified areas and the effect of their implementation will be to build age-management strategies. A comprehensive approach to age management concept involves the following steps (Liwiński \& Sztanderska, 2010b):

- focus on activities of a preventive nature designed to prevent the elimination of the employment of older workers;

- take action to employ workers of different ages, not just older;

- use the tools at the same time in all areas of age management;

- use only temporarily remedial tools for older workers who are affected by professional problems closely related to age, for example, gap competence and health problems resulting from work overload.

Prior to the implementation of a knowledge management program, the organization needs to have in the first place careful plans. Considered as the primary way to use the following tools gradually, it was possible to respond to any problems and correct the program to them. The effectiveness of the implementation of this program is determined by factors, such as: communication, training, monitoring, and evaluation.

Recruitment is of particular importance, especially when the organization is focused on an approach which aims to be evaluated by such characteristics candidate for a job, which is important from the point of view of the company. It is about the state of his knowledge and competence they need organization. However, the characteristics of age or gender are insignificant and therefore should be ignored in the recruitment process. In order to promote this approach and to overcome bad habits in this respect, it is worth remembering to write up recruitment rules clarifying the criteria taken into account in the process of employment. It is also important to include the conduct of recruitment of 50+. Advanced activities in the areas of recruitment are those that rely on the definition of the manager's job competency profiles. Preparing profiles becomes an opportunity to clarify which employee competency is required for a particular position, regardless of age (Schimanek, 2010).

There is no doubt that older workers are in a difficult situation, because they possess unique skills before they can become out of date and thus lead to the creation of knowledge and skills deficits. The decrease in the level of competence means that workers are losing hope of prolonging the working lives. This is the result of employers holding stereotypes about elder employees. Employers have questioned the sense of continued employment of people over age 50, claiming that they are working inefficiently, which shows a lack of confidence in the changes that are negative about the technological innovations. These are the reasons why business owners lose the incentive to invest in their development, what is more, even considering exempting them from work. To change this negative trend, it is necessary to reject the stereotypical image of older workers and to highlight the benefits arising out of their employment. Often the observation is that there are people with many years of experience, disciplined, and willing to engage in matters for the company. Good practice can help those companies that invest in training for managers in order to develop awareness of the management team of diverse age.

It should be emphasized that in the minds of entrepreneurs who saw the benefits of this type of employment of employees, it becomes necessary to organize vocational training aimed at increasing their 
professional qualifications. In view of the above, it is considered essential to promote the idea of lifelong learning with the use of the following tools (Liwiński \& Sztanderska, 2010a):

- ensuring access to training and other forms of training for all employees, regardless of age;

- motivating especially mature age workers to training in order to understand that knowledge is obsolete and therefore becomes necessary to raise professional qualifications as part of the training;

- monitoring the progress of training and participation of all employees, regardless of age and resource employee competencies;

- preparing a training program based on individual career and professional development of the employee: The company should provide subordinates access to training to prepare for work at a given position and contributing to the development of their careers;

- giving an ongoing comparative analysis of competence needs of organizations and competencies of employees, as well as support for training subjects diagnosed deficits: It is required to conduct such operations, regularly due to outdate competencies even after three years;

- integrating methods, place, and time of training with the needs of mature age workers;

- introducing restrictions on working time during the training;

- organizing the work in such a way to promote the learning process - creating teams whose members are employees of different ages: This allows the use of two-sided mentoring in which younger workers and older colleagues communicate knowledge of modern technology and mature age workers can pass on to younger lessons learned from work;

- preparing measures to analyze the effects of education.

As part of the age-management strategies deserve special consideration flexible forms of atypical employment on labor relations, the use of flexible forms of employment for older workers time should be aligned to their current needs and possibilities. In order to obtain more flexible working time, such hour that is conducive to improving the efficiency of workers and the reconciliation of work and personal life is determined. Older workers are showing interest in flexible working time even for reasons, such as lower physical fitness, family care responsibilities, and protection against the suspension of pension (Liwiński \& Sztanderska, 2010b). For older workers, it is reasonable to employ the following forms of employment: part-time work, reduced working hours, and telecommuting, including telecommuting, working on call, shift work, flexible working hours, and temporary work.

It cannot be unequivocally proven that human capabilities, which can have a significant impact on the ability to work effectively, change with age. Decreasing physical fitness can be compensated under the influence of factors, such as a lot of experience, knowledge, and high emotional resilience. It is worth remembering that in order to prolong the working life of employees, it is considered necessary to ensure a safe working environment in the organization. To fulfill this principle, people must ensure adaptation of work to the capabilities and personal needs of all employees, regardless of age. In the context of age management, it is essential for the development of procedures to be based on which you will be able to customize the position of older workers. The factors determining the proper development of the procedure are as the followings (Polak-Sopińska, 2013):

- a general knowledge of the changes taking place in the body of persons over 50 years of age and knowledge of basic guidelines for action to extend their working lives;

- ability to analyze the requirements on the job;

- comparison of the results of the job analysis of the possibilities of the elderly; 
- determination of the changes necessary to implement the organization and work at a given position;

- an understanding of knowledge about diseases common for people 50+;

- comparison of the results of the analysis and determination of the relationship occurring between the efficiencies and capabilities of the employee and the requirements in terms of jobs;

- adaptation of job opportunities to the individual employee.

As part of good management practices are important elements of the age of activities designed to protect health, they should be addressed to all employees regardless of age. A good solution is to use incentives to invest in additional health and accident insurance on favorable terms. They are key training organized to create awareness to employees' benefits that involve achieving aged 50+ and also threats to their health during their work (Zięba \& Szuwarzyński, 2008).

Based on experience of companies described in the literature, it can be seen that in order to coordinate the work and capabilities of older workers, they are often transferred to other job positions. Actions based on shifts can also be used as a preventive and are taken to prevent occupational diseases. It is advisable for employers to focus on employee job preparation corresponding to the psychophysical capabilities. Creation of favorable conditions of work employees makes less become workload, which in turn leads to avoiding burnout (Liwiński \& Sztanderska, 2010b).

For several years, companies are faced with the problem of shortage of skilled workers. There is even talk of a global deficit of talent that makes companies face a difficult challenge, namely, to deal with the acquisition of employees in which they care most about the desired profile in this case. Some of the companies decide to adopt a strategy that focuses on the activities of mature age workers. In the context of the concept of age management, it can venture to say that ensure that employees are career opportunities for them as an incentive to remain with the company for the next several years (Gawron \& Milewska, 2013). Thus, with the approval of the management staff belonging to age group 50+, it can take care of creating your own career means that the employee becomes an active entity responsible for the elaboration and implementation of the plan for the professional development of the road course (Fryczyńska \& Jabłońska-Wołoszyn, 2009).

Brzezińska and Paszkowska-Rogacz (2009) considered a career in terms of the subjective dimension of the human life cycle. In the case of workers belonging to the age group of 50+, the last two stages of life are critical: a stage of maturity and duration of the golden age. Mature workers are characterized by their ability to analyze their own activity in the professional sphere in terms of actual achievement. Additionally, it is worth the time spent on planning and effective implementation of their own careers. The last stage characteristic of people over 60 years of age may be a period of concern about the implementation of professional tasks, gain new experiences which was previously impossible due to adverse conditions (Brzezińska \& Paszkowska-Rogacz, 2009). As practice shows, some companies take action to guarantee development opportunities, broadening skills and knowledge to the older workers. In order to secure employment for people aged 50+, large corporations have solutions, such as (Gawron \& Milewska, 2013):

- providing feedback on your work;

- increasing accountability;

- new position;

- coaching;

- being a coach/mentor; 
- creation of knowledge bases;

- assigning new tasks;

- opinions of strategic actions;

- training.

Good practices can also be applied to the field associated with the termination of employment and retirement. According to the assumption of good practice, decisions to dismiss a worker must be based on objective criteria with regard to a particular employee. In contrast, retirement should not be equated with coercion and the employee should make a choice. The employer deciding to dismiss the employee cannot take into account the age, but should be guided by knowledge, skills, and productivity (Liwiński \& Sztanderska, 2010b). In the context of age management, good practices are also to support programs involving the use of employee outplacement method, the essence of which is to provide assistance to a person interested in seeking a new job and the creation of a system of vocational guidance (Kuciński \& Rutkiewicz, 2012).

\section{Conclusions}

In the era of an aging population and a declining number of young workers entering the labor market, there is a need for a new approach to human resource management. Therefore, it is necessary to: take measures to encourage people of mature age to stay in the company and increase their productivity; care for the effective use of the potential of all employees and maintain their maximum activity; and increase efficiency in the process of achieving organizational goals. Review of the literature provides many examples of good practice confirming the validity of the use of age management tools for the efficient use of human resources in the organization.

\section{References}

Adamczyk, J. (2009). Corporate social responsibility. Theory and practice. Warsaw: Polish Economic Publishing House.

Barrena-Martínez, J., López-Fernández, M., \& Romero-Fernandez, P. M. (2011). Research proposal on the relationship between corporate social responsibility and strategic human resource management. International Journal of Management and Enterprise Development, 10(2/3), 173-187.

Barrena-Martínez, J., López-Fernández, M., \& Romero-Fernández, P. M. (2012). Towards the seeking of hrm policies with a socially responsible orientation: A comparative analysis between Ibex-35 firms and fortune's top 50 most admired companies. Encontros Científicos-Tourism \& Management Studies, 2, 488-501.

Bernatta, M., Bogdanienko, J., \& Skoczny, T. (2011). Corporate social responsibility. Warsaw: University of Warsaw.

Biernatt, M. (2009). Corporate social responsibility. Constitutional and international dimension. Warsaw: University of Warsaw.

Brzezińska, E., \& Paszkowska-Rogacz, A. (2009). A man in the company. Warsaw: Diffin Publishing House.

Buciuniene, I., \& Kazlauskaite, R. (2012). The linkage between HRM, CSR, and performance outcomes. Baltic Journal of Management, 7(1), 5-24.

Fryczyńska M., \& Jabłońska-Wołoszyn, M. (2009). A practical guide for professional development of employees. Warsaw: Placet. Gawron, M., \& Milewska, J. (2013). The development and advancement of employees aged 50+. In P. Woszczyk and M. Czarnecka (Eds.), A man: The best investment. Methodology of age management as an innovative solution to support the economic activity of employees aged 50+. Retrieved from www.zarzadzaniewiekiem.com.pl

Kuciński, M., \& Rutkiewicz, M. (2012). Managing age as a way to stimulate people aged 50+. Bydgoszcz: Kuyavian-Pomeranian University.

Liwiński J., \& Sztanderska, J. (2010a). Initial standards for age management in companies. Warsaw: University of Warsaw.

Liwiński, J., \& Sztanderska, U. (2010b). Age management in the company. Warsaw: University of Warsaw.

Michalski, E. (2008). Management. Koszalin: Technical University of Koszalin.

Polak-Sopińska, A. (2013). Adaptation of work stations to the capabilities and needs of employees aged 50+. In P. Woszczyk and M. Czarnecka (Eds.), A man: The best investment. Methodology of age management as an innovative solution to support the 
economic activity of employees aged 50+. Retrieved from www.zarzadzaniewiekiem.com.pl

Schimanek, T. (2010). Age management-An opportunity for entrepreneurs. Mini guide for age management. Warsaw: Publisher Academy for the Development of Philanthropy.

Szcześniak, A. (2013). Good practice in age management and human resources with particular attention to employees aged 50+. Retrieved from www.zostanmentorem.pl

Szydłowska-Biskup, K. (2015). Ethical culture in a company (in) socially responsible business. Retrieved from www.zarzadzaniezasobamiludzkimi.pl

Urbaniak, B., \& Wieczorek, I. (2007). Age management of employees. In B. Urbaniak (Ed.), Employees aged 45+ in our company. Lodz: University of Lodz.

Zięba, A., \& Szuwarzyński, A. (2008). Fifty over age management (University of Technology, Faculty of Management and Economics, Gdansk). 